\title{
NASA U-turns enrage planetary scientists
}

\section{William Triplett, Washington}

Planetary scientists in the United States have criticized a string of recent cancellations of missions at NASA, warning that they may put the future health of US planetary exploration at risk.

Following NASA's fourth cancellation of a scheduled planetary science mission in two years, the American Astronomical Society's Division for Planetary Science (DPS) has issued a strongly worded statement arguing that any more cancellations would result in "excessively reduced" programme content and narrow the scope of US space research.

The latest cancellation was the nanorover, a NASA component of Japan's MUSES-C asteroid sample-return mission. That followed the abandonment of the DS4/Champollion comet mission and the Mars 2001 Lander, a follow-up to the Mars Polar Lander that failed in late 1999. In September, NASA stopped work on the Pluto-Kuiper Express mission, scheduled to launch in 2004, that was to study Pluto's atmosphere before exploring the Kuiper Belt.

NASA says the cancelled missions were plagued by cost overruns. But the planetary scientists say NASA could have tackled these by increasing the peer review of proposed missions and making the mission-proposal process an open competition. For decades, the Jet Propulsion Laboratory (JPL) in Pasadena, California, has been in charge of NASA's planetary exploration missions.

Ed Weiler, NASA's head of space science since 1998, who cancelled three of the four missions, says he would like to implement more competition. But Weiler maintains that he must first cope with the problems facing existing missions, which were all instigated by his predecessor, Wes Huntress, currently vice-chairman of the DPS.

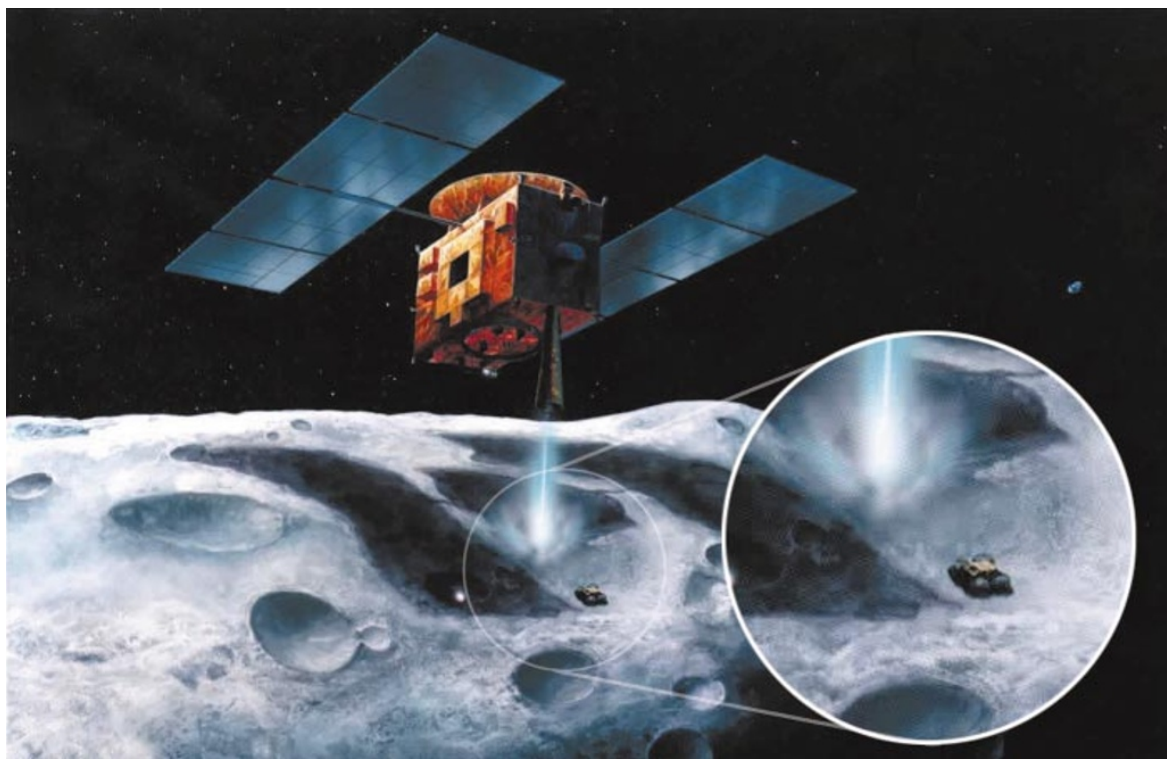

Rover's over: the nanorover (inset) on the MUSES-C asteroid mission is NASA's latest cancellation.

Weiler argues that the cancellations were unavoidable. The nanorover, for example, was priced at around $\$ 20$ million about four years ago, but the latest estimates put its cost at more than $\$ 60$ million. Similarly, the JPL put a figure of $\$ 650$ million on a two-mission package including the Pluto expedition, whereas the latest figures put the price at over $\$ 1.4$ billion.

Michael Drake, who chairs the solar system exploration subcommittee of NASA's Space Science Advisory Committee, says he is "sympathetic to NASA on this because fiscal discipline must be maintained". The space agency has been plagued by unrealistically low bids from contractors, says Drake.

But Mark Sykes, chairman of the DPS, says Weiler's hardline approach risks "throwing the baby out with the bathwater". He fears that the Europa orbiter - a mission to explore one of Jupiter's moons for signs of life - could be next for the chop.

Sykes acknowledges that NASA's plans for exploring Mars are still very much alive, but he does not want Mars to be the only planet studied.

Weiler concurs, but says: "I want to find a way to make these other outer-planet missions cheaper." He says he is considering opening missions up to bids from universities or federally funded institutions. Weiler has told the JPL that the Pluto mission could go ahead if it can cut costs on other projects.

Huntress and his allies would like to see NASA consider alternatives to cancelling missions. "There are lots of ideas out there," he says. "If one mission is running over costs, why not look for other cheaper ideas for the same mission?" request of the local government after the war, contains 56 names.

These lists are almost certainly

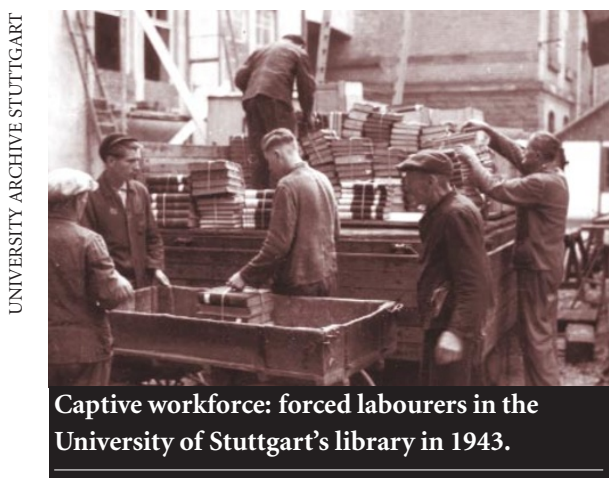

NATURE $\mid$ VOL 408 | 30 NOVEMBER 2000| www.nature.com underestimates of the true number of forced labourers. Dieter Speck, head of the archive of the University of Freiburg, which lists more than a dozen cases there, says that investigations are "very difficult and frustrating", as many records have been destroyed or handed over to the occupying forces. Extrapolating from surviving documents, he estimates that academia as a whole must have exploited several thousand forced labourers.

The Kaiser Wilhelm Society, the predecessor of the Max Planck Society, employed a "large number of forced labourers, maybe up to a thousand individuals", says Jens-Christian Wagner, a historian and member of an independent research group investigating the episode. Its findings will be published next month.

Researchers have found that a class system operated among the forced labourers. Those from the west were often considered capable of being 'Germanized' and received preferential treatment. For example, three French prisoners of war worked at the University of Freiburg in their own professions as librarians and archivists, and remained at the university after the war.

Most universities have taken few steps to contact forced labourers or their relatives. One exception is the University of Tübingen, which some years ago invited 30 former forced labourers from Poland to a reception as a gesture of apology. 